\title{
Polymer-Controlled Synthesis of Silver Nanobelts and Hierarchical Nanocolumns
}

Jingwei Bai, Yao Qin, Chengyang Jiang, and Limin Qi*

Beijing National Laboratory for Molecular Sciences (BNLMS), State Key Laboratory for Structural Chemistry of Unstable and Stable Species, College of Chemistry, Peking University, Beijing 100871,

P. R. China.E-mail: liminqi@pku.edu.cn

\section{Supporting Information}

\section{Synthesis procedure}

Silver nanobelts were readily synthesized by reducing $\mathrm{AgNO}_{3}$ with ascorbic acid in aqueous solutions of PAA $\left(M_{\mathrm{w}}=2100\right.$, sodium salt, Aldrich) at $4^{\circ} \mathrm{C}$. In a typical synthesis, $4.75 \mathrm{~mL}$ of solution containing PAA $\left(8 \times 10^{-3} \mathrm{mg}\right)$ and $\mathrm{AgNO}_{3}\left(2.5 \times 10^{-3} \mathrm{mmol}\right)$ was first prepared in a glass tube and thermostated at $0^{\circ} \mathrm{C}$. Then, $0.25 \mathrm{~mL}$ of $5 \mathrm{mM}$ ascorbic acid thermostated at $0^{\circ} \mathrm{C}$ was added with shaking, which gave a final PAA concentration of $1.6 \mathrm{mg} \mathrm{L}^{-1}$. After mixing, the solution was put in a refrigerator thermostated at $4^{\circ} \mathrm{C}$ and allowed to stand for $\sim 48 \mathrm{~h}$, leading to the gradual formation of a gray film on the inner wall of the glass tube. The film product was scratched off the glass wall and washed with water.

For the synthesis of silver hierarchical nanocolumns, acetic acid (HAc) was introduced and the solution composition was slightly adjusted with the synthesis procedure essentially unchanged. Briefly, $4.5 \mathrm{~mL}$ of solution containing PAA $\left(1.75 \times 10^{-2} \mathrm{mg}\right), \mathrm{AgNO}_{3}\left(5 \times 10^{-3} \mathrm{mmol}\right)$, and HAc $\left(1.5 \times 10^{-2} \mathrm{mmol}\right)$ was first prepared and thermostated at $0^{\circ} \mathrm{C}$. Then, $0.5 \mathrm{~mL}$ of $5 \mathrm{mM}$ ascorbic acid thermostated at $0^{\circ} \mathrm{C}$ was added with shaking, which gave a final PAA concentration of $3.5 \mathrm{mg} \mathrm{L}^{-1}$ and HAc concentration of $3 \mathrm{mM}$. After mixing, the solution was put in a refrigerator thermostated at $4^{\circ} \mathrm{C}$ and allowed to stand for $\sim 48 \mathrm{~h}$, leading to the formation of black precipitates, which were recovered and washed with water. 


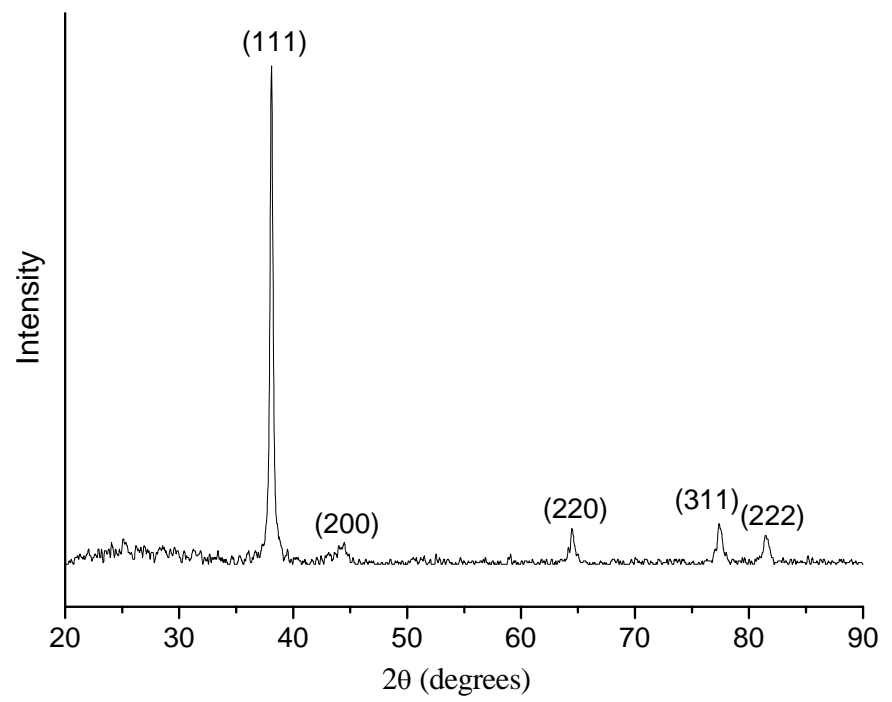

Figure S1. XRD pattern of silver nanobelts obtained at $[\mathrm{PAA}]=1.6 \mathrm{mg} \mathrm{L}^{-1}$.
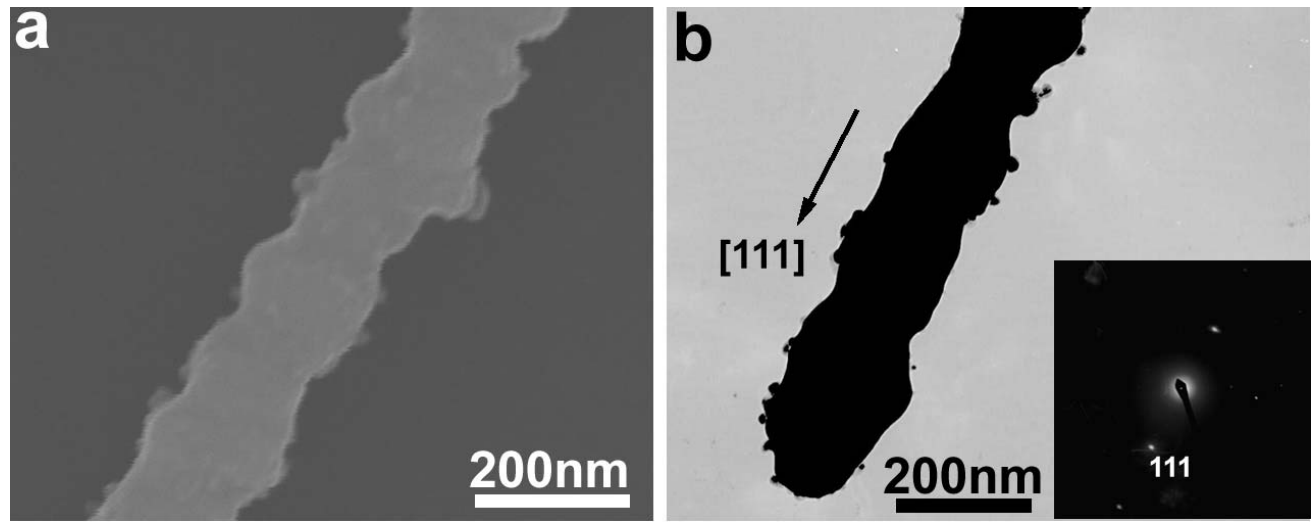

Figure S2. SEM (a) and TEM (b) images of silver nanocolumns after partially dissolved by $\mathrm{HNO}_{3}$. Inset shows the corresponding ED pattern. 